\title{
SIMULASI APLIKASI TRYOUT UJIAN NASIONAL BERBASIS KOMPUTER (UNBK) ONLINE DI SMA KABUPATEN CIREBON
}

\author{
Herri Sulaiman, Trusti Hapsari, Tonah, dan Fuad Nasir \\ Prodi Pendidikan Matematika, FKIP, Universitas Swadaya Gunung Jati \\ E-mail : herrimsc@gmail.com
}

\begin{abstract}
ABSTRAK
Ujian merupakan salah satu bentuk evaluasi yang diadakan setelah proses belajar mengajar berlangsung. Banyaknya kelulusan dari suatu sekolah, mencerminkan kemajuan serta keberhasilan di sekolah tersebut. Data kelulusan di kabupaten Cirebon tahun ajaran 2017/2018 untuk SMA/SMK adalah 5.033 untuk siswa laki-laki dan 1.989 untuk siswa perempuan. Pada saat itu Ujian Nasional sudah berbasis komputer, sedangkan sekolah yang melaksanakan ujian nasional berbasis komputer hanya 8 sekolah dari 38 SMK dan 4 dari 28 SMA yang ada. Data tersebut menunjukkan bahwa masih diperlukan adanya perbaikan untuk meningkatkan kualitas pendidikan. Pada awalnya, ketika siswa melaksanakan ujian nasional menggunakan naskah tertulis, siswa masih merasakan kesulitan. Mulai dari saat menjawab soal, melingkari jawaban pada lembar jawab yang apabila salah melingkari dapat berakibat fatal pada hasil ujian yang diperoleh. Sehingga diberlakukan suatu program tryout yang digunakan sebagai sarana latihan siswa dalam menghadapi ujian nasional. Kegiatan pengabdian ini bertujua nuntuk memudahkan siswa dalam berlatih dalam mengerjakan soal ujian berbasis komputer. Berdasarkan hal tersebut maka nantinya akan dijadikan sebagai percontohan dalam program ini. Meskipun telah melaksanakan ujian nasional berbasis komputer, namun belum sepenuhnya berjalan sesuai dengan harapan karena masih kurangnya persiapan untuk melakasanakan UNBK. Metode pelaksanaan kegiatan pengabdian aplikasi tryout ujian online untuk SMA/SMK sederajat meliputi 5 tahap yaitu Analysis (analisis), Design (perencanaan), Development (produksi), Implementation (implementasi), Evaluation (evaluasi). Hasil kegiatan pengabdian PPM ini berupa (1) Aplikasi Tryout ujian online (2) Manual book untuk ditujukan untuk semua pengguna aplikasi, baik guru, siswa, maupun admin aplikasi.
\end{abstract}

Kata Kunci : tryout, aplikasi, ujian nasional berbasis komputer (unbk)

\section{PENDAHULUAN}

Salah satu terobosan baru dari pemerintah dalam pendidikan yaitu diadakannya Ujian Nasional Berbasis Komputer (UNBK). Pengertian UNBK itu sendiri yang juga diterangkan dalam Peraturan Badan Standar Nasional Pendidikan

(BSNP)

0043/P/BSNP/I/2017 adalah ujian yang menggunakan komputer sebagai media untuk menampilkan soal dan proses menjawabnya. Pelaksanaan UNBK itu sendiri menjadi perubahan penerapan pengembangan metode evaluasi belajar mengajar yang dahulu masih bersifat konvensional diarahkan ke arah yang lebih modern dan efektif sehingga diharapkan proses kegiatan evaluasi ini 
menjadi lebih optimal dalam peran dan fungsionalnya. Fakta bahwa peran teknologi informasi dan komunikasi dalam menunjang proses pembelajaran dewasa ini sangat berkembang pesat (Darmawan, 2012). Selain itu dari hasil penelitian Zarlis (2001) dan Astawa menyimpulkan bahwa penggunaan media berbasis komputer akan meningkatkan pemahaman peserta didik secara umum. Pada tahun 2015, pemerintah telah mulai menjalankan program UN Online. Di satu sisi kebijakan ini sangatlah baik, mengingat sifat komputer yang dapat bekerja cepat, tepat, dan tidak subjektif, sehingga diharapkan mengurangi tingkat kecurangan pelaksanaan UN dan juga menghemat biaya ujian nasional. Namun disisi lain pasti akan muncul beberapa keraguan akan kebijakan UN Online ini, seperti kesiapan sarana prasarana dan juga kesiapan siswa.

Dari sudut pandang siswa, ketegangan saat mengerjakan soal-soal UN pasti akan bertambah karena beberapa kekurang nyamanan yang diakibatkan penggunaan komputer. Namun semua kekurang nyamanan sistem berbasis komputer akan dapat dikurangi dengan latihan, sehingga siswa terbiasa dan memahami tips yang benar dalam mengerjakan ujiannya. Kementrian Pendidikan Dasar sebenarnya sudah menciptakan sebuah sistem latihan ujian nasional berbasis komputer, sehingga diharapkan para siswa bisa berlatih sambil menyesuaikan diri mereka mengerjakan ujian nasional berbasis komputer. Namun tidak semua siswa, terutama yang ada di daerah memiliki koneksi internet dirumah untuk mengakses sistem tersebut. Di sekolah pun dengan kuota internet terbatas maka akan sulit untuk mengakses dengan baik sistem latihan tersebut. Sehingga bagi siswa yang motivasinya kurang akan malas untuk berlatih. Permasalahan ini diungkapkan salah satu mitra pengabdian yaitu salah satu SMA N di Kab. Cirebon. Walaupun demikian sebagai sekolah binaan propinsi ini dituntut untuk siap melaksanakan sistem UN online. Sejalan dengan permasalahan yang dihadapi mitra, pihak Dinas Pendidikan kabupaten Cirebon melalui sub dinas pendidikan dasar-nya juga mengungkapkan kegelisahannya terhadap rencana pelaksanaan UN online, sehingga pihak dinas mengarahkan pelaksana untuk memilih SMA $\mathrm{N}$ yang merupakan 
sekolah percontohan binaan provinsi sebagai mitra kegiatan.

Program PKM ini merupakan permintaan dan hasil diskusi dengan pihak sekolah. Mitra telah memiliki sarana dan prasarana pembelajaran berbasis komputer yang baik, seperti lab multimedia maupun koneksi internet. Namun seringkali sarana dan prasarana tersebut kurang dimanfaatkan secara optimal. Apalagi dengan kebijakan kurikulum yang menghapus mata pelajaran TIK, membuat lab multimedia tersebut semakin jarang digunakan dalam proses belajar mengajar. Sedangkan disisi lain mereka memiliki masalah dalam mempersiapkan siswa untuk terbiasa mengerjakan ujian nasional berbasis komputer. Berdasarkan hal tersebut, dirasakan sangat perlu untuk membantu pihak sekolah mitra dalam merancang dan membangun sistem dalam mengisi konten soal-soal ujian nasional elearning yang akan dibangun dengan latihan yang berisi soal-soal ujian nasional. Permasalahan lain yang muncul adalah kurangnya keterampilan guru dalam mengisi konten pembelajaran pada sistem e-learning, sehingga melalui kegiatan pengabdian ini melakukan pendampingan bagi para guru dalam mengisi konten e-learning mereka.

\section{METODE PELAKSANAAN}

Metode kegiatan yang dilakukan dalam pelaksanaan PPM ini sebagai berikut :

a. Observasi ke sekolah mitra untuk melihat keadaan langsung permasalahan yang dialami oleh mitra.

b. Pada saat perencanaan, tim PPM membuat dan mendesain terlebih dahulu sistem e-learning untuk soal-soal UN dan dapat ditunjukkan kepada guru-guru sebagai contoh.

c. Tahap pelaksanaan, tim PPM menyiapkan segala sesuatu yang diperlukan untuk kegiatan pengabdian berlangsung, termasuk koneksi internet, persediaan laptop dan terminal listrik.

d. Tahap pendampingan dan kolaborasi. Pada tahap ini, tim PPM memonitoring dan mengevaluasi sejauh mana kemampuan mitra dalam mengoperasikan komputer dan menggunakan sistem $e$ learning dengan benar. Pendampingan dapat dilakukan secara berkala. 
Dari penjelasan di atas mengenai solusi yang ditawarkan oleh tim PPM untuk mangatasi permasalahan yang dihadapi oleh mitra, maka berikut ini diberikan tabel yang menyatakan jenis luaran yang akan dihasilkan dari masing-masing solusi pada kegiatan PPM ini.

\begin{tabular}{|c|c|c|c|}
\hline No. & $\begin{array}{c}\text { Permasalahan yang Dialami } \\
\text { Mitra }\end{array}$ & Solusi & Luaran \\
\hline 1. & $\begin{array}{llr}\text { Kesiapan siswa } & \text { dalam } \\
\text { menyongsong } & \text { UNBK } & \text { SMA } \\
\text { masih kurang. } & & \\
\end{array}$ & $\begin{array}{l}\text { Perlu adanya latihan } \\
\text { dalam } \\
\text { menyelesaikan soal- } \\
\text { soal UNBK. }\end{array}$ & $\begin{array}{lr}\text { Sistem } & \text { e-learning } \\
\text { yang } & \text { berisi } \\
\text { kumpulan } & \text { soal- } \\
\text { soal UN. } & \end{array}$ \\
\hline 2. & $\begin{array}{l}\text { Mitra masih mengalami } \\
\text { kesulitan dalam } \\
\text { mengoperasikan komputer dan } \\
\text { mengisi konten-konten soal } \\
\text { UN ke dalam sistem e- } \\
\text { learning. }\end{array}$ & $\begin{array}{l}\text { Diadakan pelatihan } \\
\text { dalam } \\
\text { pengoperasian } \\
\text { komputer untuk } \\
\text { mengisi konten- } \\
\text { konten soal UN ke } \\
\text { dalam sistem e- } \\
\text { learning. }\end{array}$ & $\begin{array}{l}\text { Peningkatan } \\
\text { keprofesionalitas, } \\
\text { kualitas dan } \\
\text { kompetensi guru- } \\
\text { guru sekolah } \\
\text { menengah atas. }\end{array}$ \\
\hline
\end{tabular}

\section{Tabel 1. Permasalahan Mitra dan Solusi dari tim PPM}

Pada kegiatan ini, tim PPM mendatangi lokasi disalah satu sekolah menengah atas di kabupaten Cirebon. Setelah itu melakukan penandatangan MoU dengan mitra yang diwakilkan oleh kepala sekolah. Metode program yang dilaksanakan merupakan sebuah rangkaian yang rinci dan sistematis, diantaranya : (1) perencanaan dan persiapan, (2) sosialisasi dan bekerja sama dengan mitra (dalam hal ini guru SMA), (3) penyuluhan dan pelatihan pengoperasian komputer dan pengisian konten-konten soal soal UN ke dalam sistem e-learning kepada mitra, (4) pendampingan dan bimbingan kepada mitra saat implementasi sistem elearning kepada siswa, (5) kembali melakukan monitoring dan evaluasi kepada mitra saat uji coba tryout soalsoal UN dengan sistem e-learning. Apabila ada hambatan dan kendala maka tim PPM dapat memberikan solusi agar hambatan yang terjadi segera dapat teratasi.

Metode pendekatan yang ditawarkan oleh tim PPM yaitu dengan pendekatan persuasif. Artinya tim PPM mengajak secara halus dan santun kepada mitra dalam mengikuti 
serangkaian kegiatan pelaksanaan program yang tim PPM susun. Adapun metode pelaksanaan kegiatan yang ditawarkan oleh tim PPM untuk mendukung pengabdian ini diantaranya ialah:

a. Penyuluhan

Metode penyampaian informasi untuk materi yang bersifat umum dan teoritis. Contohnya ialah penyuluhan tentang pengoperasian komputer dan menggunakan elearning dalam uji coba soal-soal tryout UN. Selain itu penyuluhan tentang pentingnya mengembangkan pengetahuan konten pedagogik yang salah satunya melalui penguasaan IT bagi guru-guru SMA.

b. Pelatihan

Metode tersebut untuk menanamkan kecakapan dan keterampilan praktis. Contohnya pelatihan dalam mengoperasikan sistem e-learning dan memasukkan konten-konten soal UN ke dalamnya.

c. Pendampingan

Metode ini diterapkan agar diperoleh hasil pelatihan yang optimal. Pada tahap ini guru melakukan implementasi dengan mengujicobakan sistem e-learning kepada siswa SMA sebagai simulasi untuk UNBK. Konten soal-soal yang diambil ialah soalsoal UN.

Kegiatan pengabdian ini akan terkait secara langsung bahkan terintegratif dengan tugas rutin mitrasebagai pendidik untuk siswa SMA. Adapun partisipasi mitra dalam pelaksanaan kegiatan PPM ini cukup antusias. Hal ini ditandai dengan adanya permintaan beberapa mitra untuk mengarahkan dan membimbing dalam pengoperasian sistem e-learning dan meminta untuk mengarahkan dalam mengisi konten-konten soal UN ke dalam sistem $e$-learning tersebut.

\section{HASIL DAN PEMBAHASAN}

Lembaga Pengabdian Masyarakat Unswagati (LPM-UGJ) Cirebon selama setahun terakhir ini telah melakukan banyak sekali program pengabdian kepada masyarakat. Selain diselenggarakannya kegiatan rutin Kuliah Kerja Nyata (KKN) dengan periode setahun 2 kali, yang disebar di daerah kabupaten Cirebon untuk 7 Fakultas. Program LPM UGJ juga memberikan layanan fasilitas berupa kesempatan kepada dosen-dosen di 
dalam lingkungan instansi untuk mengadakan pengabdian kepada msyarakat dengan memberikan dana stimulus kepada dosen-dosen tersebut. Kegiatan ini dapat dilaksanakan setahun 2 kali, di luar program KKN. Dampak dari kegiatan ini dapat dirasakan oleh warga Cirebon untuk daerah perkotaan maupun kabupaten. Contohnya ialah bidang pendidikan banyak sekali diantara warga yang merasa terbantu dan terlayani ketika mereka belajar untuk membaca dan menulis. karena perlu diketahui bahwa masih ada warga yang buta aksara. Hal ini sering kali ditemukan di wilayah kabupaten dekat dengan pesisir pantai. Jenis kepakaran yang diperlukan dalam menyelesaikan seluruh persoalan atau kebutuhan mitra yaitu :

Berikut ini diberikan tabel mengenai tim nama pengusul beserta kepakaran dan tugas masing-masing.

\begin{tabular}{llll}
\hline No. & Nama Pengusul & \multicolumn{1}{c}{$\begin{array}{c}\text { Bidang } \\
\text { Kepakaran }\end{array}$} & \multicolumn{1}{c}{ Tugas } \\
\hline \multicolumn{4}{c}{ Tim Pengabdian Kepada Masyarakat (PKM) } \\
\hline 1. Herri Sulaiman, S.Si, M.Sc & $\begin{array}{l}\text { Pendidikan } \\
\text { Matematika }\end{array}$ & $\begin{array}{l}\text { Penanggungjawab, Membina } \\
\text { dan Membimbing Mitra. }\end{array}$ \\
2. Dr. Trusti Hapsari, S.Si, & $\begin{array}{l}\text { Pendidikan } \\
\text { Matematika }\end{array}$ & $\begin{array}{l}\text { Melatih dan mengisi materi } \\
\text { pelatihan }\end{array}$ \\
M.Pd & Pendidikan & $\begin{array}{l}\text { Melatih dan mengisi materi } \\
\text { pelatihan. }\end{array}$ \\
3. Drs. Fuad Nasir, M.Si & Matematika & $\begin{array}{l}\text { Melatih dan mengisi materi } \\
\text { pelatihan. }\end{array}$ \\
4. Tonah, S.Si, M.Si & Pendidikan & Matematika
\end{tabular}

\section{Tabel 2. Kepakaran dalam melaksanakan kegiatan pengabdian masyarakat}


Lebih lanjut berikut ini diberikan tampilan bentuk dari sistem UNBK online yang telah didesain. Tim PPM bekerjasama dengan operator IT untuk membuat sistem berbasis WEB dan melakukan perluasan domain dan hostingnya.
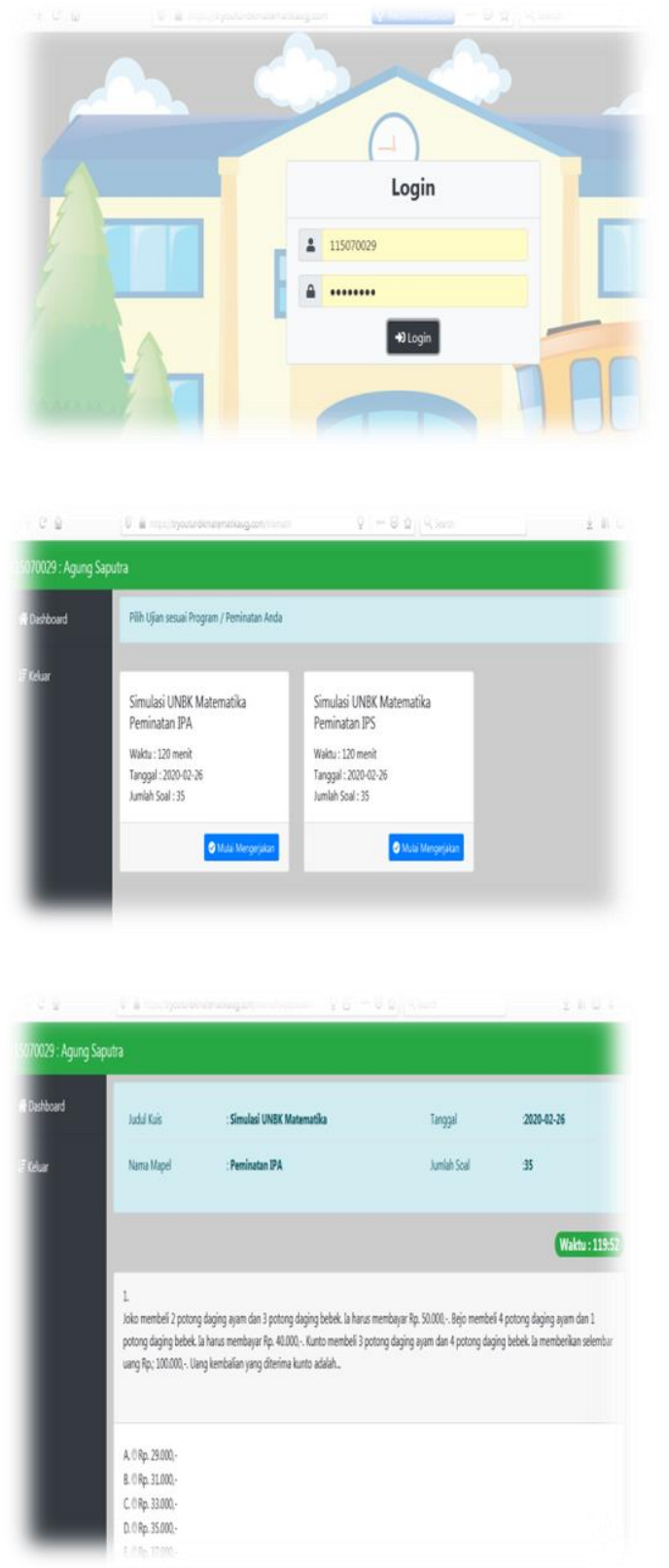
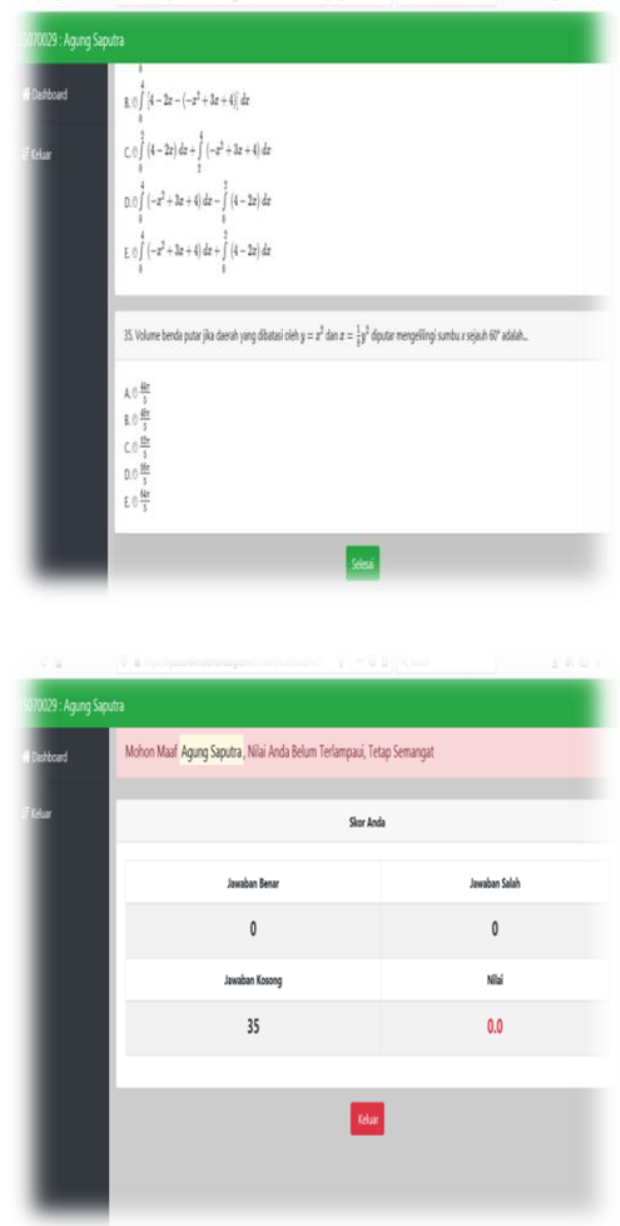

\section{Gambar 1-5. Tampilan sistem UNBK} Online untuk mata pelajaran SMA

\section{IPA dan IPS}

Selanjutnya berikut ini diberikan dokumentasi saat kegiatan simulasi UNBK Online di kelas peminatan XII IPA dan IPS di salah satu SMA N Kabupaten Cirebon, Jawa Barat. Pada saat pelaksanaan siswa diperkenankan untuk membawa laptop ataupun Smartphone yang bertipe android. Setelah itu secara serentak simulasi tryout UNBK online dilaksanakan. 

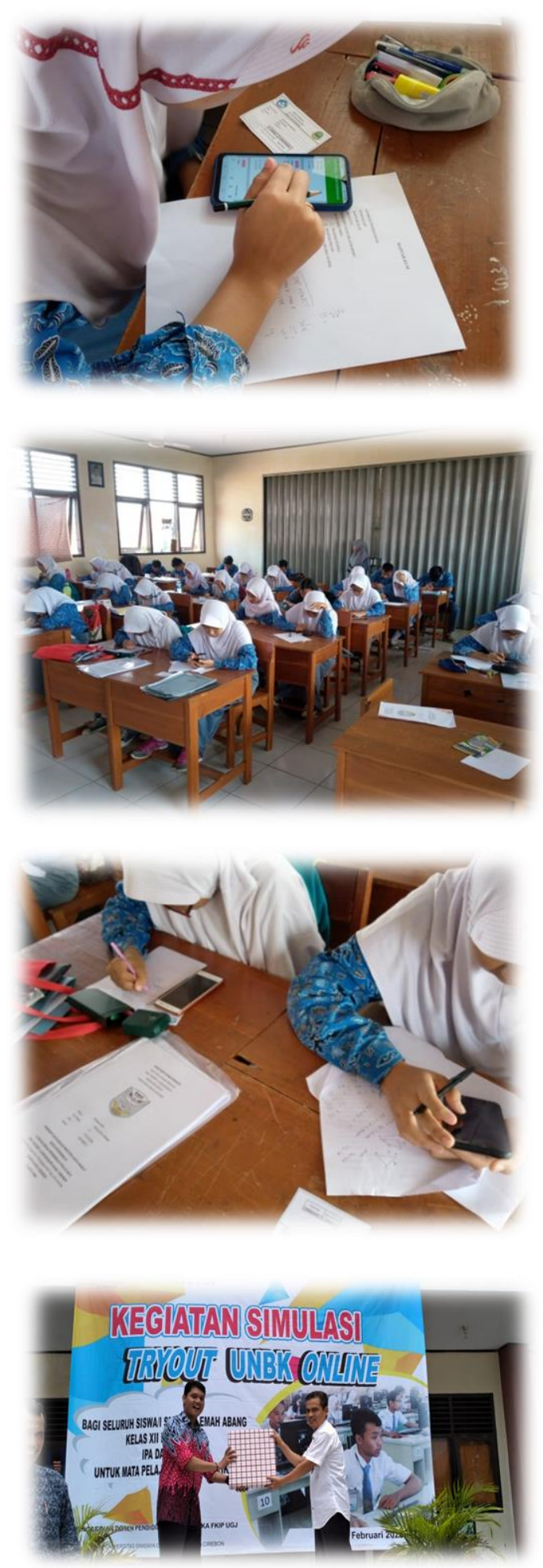

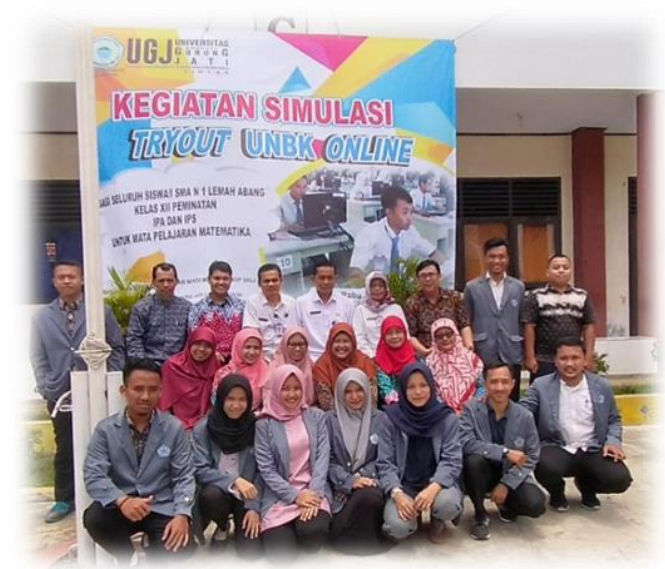

\section{Gambar 6-10. Dokumentasi saat} pelaksanaan PPM Simulasi Tryout UNBK Online

Pada saat pelaksanaan kegiatan PKM, semua berjalan dengan sukses dan lancar. Hal ini karena dukungan dari berbagai pihak yang turut serta membantu agar pelaksanaan kegiatan pengabdian ini dapat berjalan dengan lancar. Agar dapat mengetahui respon pengguna yaitu dalam hal ini siswa yang mengerjakan soal-soal simulasi UNBK online maka tim PPM menyebarkan angket respon pengguna. Dengan populasi sebesar 1500 siswa dan sampel sebesar 315 siswa. 
Berikut ini adalah hasil angket respon pada bentuk tabel di bawah ini.

\begin{tabular}{|c|c|c|c|c|c|}
\hline \multirow{2}{*}{ No } & \multirow{2}{*}{ Pernyataan } & \multicolumn{4}{|c|}{ Jawaban } \\
\hline & & SS & $\mathbf{S}$ & $\mathbf{T S}$ & STS \\
\hline 1. & $\begin{array}{l}\text { Saya menyukai pelajaran matematika dari jenjang } \\
\text { SD, SMP hingga sekarang. }\end{array}$ & $\begin{array}{l}15 \\
\%\end{array}$ & $\begin{array}{l}45 \\
\%\end{array}$ & $\begin{array}{l}40 \\
\%\end{array}$ & - \\
\hline 2. & $\begin{array}{l}\text { Ujian dengan menggunakan sistem UNBK online } \\
\text { memudahkan saya untuk mengetahui hasil skornya } \\
\text { dengan cepat. }\end{array}$ & $\begin{array}{l}90 \\
\%\end{array}$ & $\begin{array}{l}10 \\
\%\end{array}$ & & \\
\hline 3. & $\begin{array}{l}\text { Ujian dengan menggunakan sistem UNBK online } \\
\text { tidak ada bedanya dengan ujian menggunakan paper } \\
\text { based test (ujian tulis). }\end{array}$ & - & $\begin{array}{l}10 \\
\%\end{array}$ & $\begin{array}{l}15 \\
\%\end{array}$ & $\begin{array}{l}75 \\
\%\end{array}$ \\
\hline 4. & $\begin{array}{l}\text { Saya lebih bersemangat belajar matematika setelah } \\
\text { mengikuti tryout UNBK online ini. }\end{array}$ & $\begin{array}{l}55 \\
\%\end{array}$ & $\begin{array}{l}40 \\
\%\end{array}$ & $5 \%$ & - \\
\hline 5. & 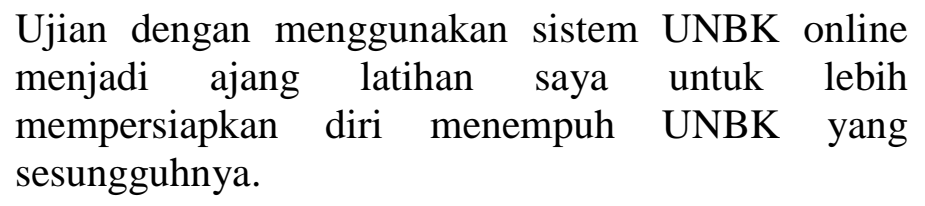 & $\begin{array}{l}80 \\
\%\end{array}$ & $\begin{array}{l}20 \\
\%\end{array}$ & - & - \\
\hline 6. & $\begin{array}{l}\text { Saya kurang berminat mempelajari matematika, dan } \\
\text { dengan adanya tryout UNBK online ini justru } \\
\text { menambah ketidaksukaan saya dalam belajar } \\
\text { matematika. }\end{array}$ & $5 \%$ & $\begin{array}{l}25 \\
\%\end{array}$ & $\begin{array}{l}60 \\
\%\end{array}$ & $\begin{array}{l}10 \\
\%\end{array}$ \\
\hline 7. & $\begin{array}{l}\text { Soal-soal UNBK online ini terlalu sulit bagi saya } \\
\text { untuk mengerjakannya. }\end{array}$ & $\begin{array}{l}10 \\
\%\end{array}$ & $\begin{array}{l}30 \\
\%\end{array}$ & $\begin{array}{l}35 \\
\%\end{array}$ & $\begin{array}{l}25 \\
\%\end{array}$ \\
\hline 8. & $\begin{array}{l}\text { Saya sudah mengetahui pengumuman adanya tryout } \\
\text { UNBK online dari guru saya, sehingga saya dapat } \\
\text { mempersiapkan diri dengan belajar untuk } \\
\text { menghadapi tryout UNBK online ini. }\end{array}$ & $\begin{array}{l}35 \\
\%\end{array}$ & $\begin{array}{l}35 \\
\%\end{array}$ & $\begin{array}{l}25 \\
\%\end{array}$ & $5 \%$ \\
\hline 9. & $\begin{array}{l}\text { Saya suka sekali mengerjakan soal melalui tryout } \\
\text { UNBK online ini karena saya menyukai segala } \\
\text { sesuatu yang ada kaitannya dengan IT (Program } \\
\text { Komputer). }\end{array}$ & $\begin{array}{l}45 \\
\%\end{array}$ & $\begin{array}{l}30 \\
\%\end{array}$ & $\begin{array}{l}25 \\
\%\end{array}$ & - \\
\hline 10. & $\begin{array}{l}\text { Saya lebih terbiasa menggunakan ujian tulis daripada } \\
\text { menggunakan sistem UNBK online ini. }\end{array}$ & - & - & $\begin{array}{l}75 \\
\%\end{array}$ & $\begin{array}{l}25 \\
\%\end{array}$ \\
\hline 11. & $\begin{array}{l}\text { Saya berharap sering ada tryout UNBK online seperti } \\
\text { ini karena menjadi ajang untuk persiapan saya dalam } \\
\text { belajar menghadapi UNBK dan SBMPTN tahun ini. }\end{array}$ & $\begin{array}{l}95 \\
\%\end{array}$ & $5 \%$ & - & - \\
\hline 12. & $\begin{array}{l}\text { Saya berharap soal soal UNBK online ini tidak } \\
\text { hanya mata pelajaran matematika saja melainkan } \\
\text { mata pelajaran lain yang diujikan di UNBK dan } \\
\text { SBMPTN. }\end{array}$ & $\begin{array}{c}100 \\
\%\end{array}$ & . & - & - \\
\hline
\end{tabular}

Tabel 3. Hasil Angket Respon Pengguna Terhadap Sistem UNBK Online 
Dari hasil angket resspon dapat diketahui bahwa mayoritas pengguna sistem UNBK online memilih bahwa sistem ini sangat layak digunakan dan mereka merasa terbantu untuk lebih mempersiapkan diri dalam menghadapi ujian nasional berbasis CBT yang sesungguhnya. Selain itu berdasarkan hasil wawancara dengan guru mata pelajaran matematika juga dapat diketahui bahwa sistem ujian online ini dapat dijadikan sarana untuk melatih siswa agar lebih siap dalam menghadapi ujian berikutnya. Selain itu soal-soal yang dikemas juga berdasarkan kisi-kisi yang sesuai dengan UN tahun 2020 ini.

\section{KESIMPULAN}

Sistem UNBK online yang telah dibuat melalui web dengan memperluas domain dan hosting agar dapat dipengguna dalam mengerjakan soalsoal UNBK online dengan lancar. Selain itu soal-soal UN untuk mata pelajaran matematika disusun berdasarkan kisi-kisi yang sesuai dengan tahun 2020 ini. Berdasarkan hasil angket respon untuk pengguna dari sistem tryout UNBK online ini menyatakan bahwa lebih dari $70 \%$ pengguna merasa puas akan sistem UNBK online dan mereka menganggap sistem ini dapat dijadikan ajang latihan mereka untuk menghadapi UNBK yang sesungguhnya.

\section{DAFTAR PUSTAKA}

Astawa Santi. (2011), Sistem Tutorial Adaptif untuk Pembelajaran Aritmetika Tingkat Sekolah Dasar, Tesis, Universitas Gadjah Mada, Yogyakarta.

Badan Standar Nasional Pendidikan. 2009. Prosedur Operasi Standar(POS)Ujian Nasional (UN) Sekolah Menengah Atas/Madrasah Aliyah (SMA/MA) Tahun Pelajaran 2009/2010. Jakarta.

Darmawan Deni. (2012), Inovasi Pendidikan, Remaja Rosdakarya Pendidikan Offset, Bandung.

Deek,FP., J.A.M.McHugh, dan O.M.Eljabiri. 2005. Strategic Software Engineering: An Interdisciplinary Approach. AuerbachPublications.

Roy, Van, dan Haridi. 2004. Concept, Technique and Models of Computer Programming. The MIT Press.

Sugiyono. 2009. Metode Penelitian Kuantitatif Kualitatif dan $R \& D$.Bandung: Alfabeta.

Zarlis. M. (2000), Sistem Tutorial Cerdas dalam Pengajaran Kaidah Berangka bagi Penyelesaian Model Matematik Kamiran dalam Fisik, Disertasi, Universiti Sains Malaysia 